\title{
Uma proposta de material didático baseado nas espécies de Vochysiaceae existentes em uma trilha no cerrado de Bauru - SP
}

\author{
Mariana Ninno Rissi ${ }^{1,3}$ \& Osmar Cavassan ${ }^{2}$ \\ ${ }^{1}$ Programa de Pós-graduação em Ciências Biológicas (Biologia Vegetal), Instituto de Biociências, \\ Universidade Estadual Paulista - UNESP, Av. 24A, 1515, CEP 13506-900, Rio Claro, SP, Brazil, \\ http://www.rc.unesp.br \\ ${ }^{2}$ Departamento de Ciências Biológicas, Faculdade de Ciências, Universidade Estadual Paulista - UNESP, \\ Av. Engenheiro Luiz Edmundo Carrijo Coube, 14-01, CEP 17033-360, Bauru, SP, Brazil, \\ $h t t p: / / w w w . f c . u n e s p . b r$ \\ ${ }^{3}$ Autor para correspondência: Mariana Ninno Rissi, e-mail: mariananinno@yahoo.com.br
}

RISSI, M.N. \& CAVASSAN, O. A proposal for teaching material based on existing Vochysiaceae species on a trail in the cerrado of Bauru - SP. Biota Neotrop. 13(1): http://www.biotaneotropica.org.br/v13n1/en/ abstract?article+bn00213012013

\begin{abstract}
This work was accomplished in a trail located inside a legal reserve in the Campus of UNESP (Universidade Estadual Paulista) in Bauru, characterized especially by the "cerrado" vegetation (savanna). The area has been used for practical field activities of the project "Wandering and Learning in the cerrado" in which students are guided into a practical class about Ecology and Botany. The family Vochysiaceae was chosen for having the greatest representativeness in this environment, besides it holds species with typical morphology from cerrado species: twisted and corky stems and some species with leathery leaves. It also allows the illustration of various ecological interactions through live examples during the field practice class. The identified species were: Qualea cordata Spreng., Qualea grandiflora Mart., Qualea multiflora Mart., Qualea parviflora Mart., Vochysia cinnamomea Pohl and Vochysia tucanorum Mart. Such species were described and samples herborized. Information about ethnobotanical and ecological interactions were searched in the literature and observed in the field. With these data it was elaborated a species catalog, an identification key and a glossary. Such tools are intended to support the practical activity of the teacher in the practical activity and to promote motivation and interest among the students.
\end{abstract}

Keywords: biodiversity, botany teaching, practical field activity, cerrado.

RISSI, M.N. \& CAVASSAN, O. Uma proposta de material didático baseado nas espécies de Vochysiaceae existentes em uma trilha no cerrado de Bauru - SP. Biota Neotrop. 13(1): http://www.biotaneotropica.org. br/v13n1/pt/abstract?article+bn00213012013

Resumo: Este trabalho foi realizado em uma trilha localizada na Reserva Legal do Campus de Bauru da UNESP, caracterizada especialmente por vegetação de cerrado. Este espaço é utilizado para o desenvolvimento de atividades práticas de campo de um projeto denominado "Passeando e aprendendo no cerrado", no qual alunos dos três níveis de escolaridade são guiados para uma aula prática de Ecologia e Botânica. A família Vochysiaceae foi escolhida como objeto da proposta por ter grande representatividade neste ambiente e possuir elementos com morfologia típica das espécies de cerrado: caules tortuosos, suberosos e algumas espécies com folhas coriáceas. O grupo possibilita ainda a visualização de diversas interações ecológicas durante aula prática de campo. As espécies identificadas foram: Qualea cordata Spreng., Qualea grandiflora Mart., Qualea multiflora Mart., Qualea parviflora Mart., Vochysia cinnamomea Pohl e Vochysia tucanorum Mart. Tais espécies foram descritas, herborizadas e fotografadas. As informações sobre etnobotânica e interações ecológicas foram buscadas na literatura e observadas em campo. A partir destes dados, foram elaborados: um catálogo de espécies, uma chave de identificação e um glossário. Tais ferramentas propõem auxiliar a atividade prática do docente e tornar o estudo destes tópicos mais motivadores e interessantes aos alunos.

Palavras-chaves: biodiversidade, ensino de botânica, aula prática de campo, cerrado. 


\section{Introdução}

O conhecimento da diversidade vegetal do cerrado paulista é obtido a partir de levantamentos florísticos e fitossociológicos de fragmentos remanescentes da cobertura original desta vegetação. Dessa forma, são obtidas listas de espécies divulgadas entre pesquisadores, cuja utilização fica restrita à academia, bem como as questões relacionadas à sua preservação, manejo ou etnobotânica. Pesquisadores assumem para si o direito e responsabilidade em deter e utilizar tais conhecimentos, disponibilizando-os para os órgãos públicos, quando solicitados. Ninguém pode negar o valioso laboratório natural inserido em cada um desses fragmentos, que constituem também o ambiente das populações humanas que vivem nas proximidades. Pessoas, que, em sua história, andaram pelo cerrado em busca de lenha, caças, frutas ou ervas medicinais. Aprenderam a reconhecer plantas e animais pelo seu nome popular, em uma relação que não foi apenas utilitarista, mas envolveu questões emocionais, afetivas e estéticas. Este é o aprendizado informal, geralmente motivador e que ocorreu a partir da necessidade de responder alguma pergunta. O que se verifica em botânica é que o ensino formal não considera esta forma de aprendizagem. Os livros didáticos são recheados com informações obtidas em manuais estrangeiros e, muitas vezes desatualizadas. Quando se busca no conteúdo de ciências e biologia do ensino fundamental ou médio um exemplo de ecossistemas terrestres, são apresentados organismos e biomas exóticos (Cavassan et al. 2009). Assim muitos alunos vivem em dois mundos: um, o mundo da experiência fora da escola; outro, o mundo dos livros e das lições (Dewey 1959). Sabe-se que muitos professores evitam as aulas de botânica, relegando-as ao final da programação do ano letivo, por medo e insegurança em falar do assunto. Uma das maiores reclamações destes docentes é a dificuldade em desenvolver atividades práticas que despertem a curiosidade do aluno e mostrem a utilidade daquele conhecimento no seu dia-a-dia. Será tão difícil montar aulas práticas em botânica?

Atividades desenvolvidas no ambiente natural, como em uma trilha, vão além de uma simples aula prática. Dependendo de como esta é organizada, pode permitir que o aluno elabore suas próprias interpretações dos conteúdos envolvidos e reflita sobre e através dos fenômenos naturais com a vantagem adicional e diferencial de estar no ambiente a ser estudado.

Este estudo está contido no projeto de pesquisa "Biodiversidade no Cerrado: uma proposta de trabalho prático de campo no Ensino de Botânica e Ecologia nos três níveis de escolaridade", que visa o conhecimento da diversidade vegetal de um fragmento de cerrado em Bauru e a divulgação desta diversidade aos alunos e professores dos ensinos em níveis fundamental, médio e superior. Neste projeto busca-se contribuir com os professores dos três níveis de escolaridade do município de Bauru e demais cidades da região, propondo uma atividade de campo na qual os alunos possam ter um contato direto com a biodiversidade do cerrado. Assim, objetiva-se também sensibilizá-los quanto à preservação deste bioma, além de contextualizar conceitos botânicos e ecológicos vistos em sala de aula.

Inúmeros trabalhos foram desenvolvidos dentro deste projeto, discutindo a importância do uso de ambientes naturais para aulas de botânica e ecologia (Cavassan et al. 2006, 2009, Pinheiro da Silva et al. 2009). Nestes, verificou-se a demonstração de atitudes motivadas para o aprendizado de botânica (Seniciato \& Cavassan 2008a), a formação de conceitos científicos em aulas de campo (Seniciato \& Cavassan 2008b) e a formação de valores estéticos sobre ambientes naturais (Seniciato et al. 2006, Seniciato \& Cavassan 2009). Com estes estudos teve-se como objetivo ultrapassar os limites das aulas de botânica, onde as práticas educativas restringem-se ao domínio cognitivo, muitas vezes revestindo-se de caráter utilitarista e pragmático. No entanto, não se pode prescindir do conhecimento científico atualizado. Nenhuma estratégia pedagógica é suficiente se o conteúdo é incorreto ou desatualizado. Para isso, tornou-se importante o conhecimento mais profundo das características botânicas e ecológicas do cerrado lá existente. Uma das maneiras de buscar esse conhecimento é a partir da caracterização de cada táxon componente de sua flora. Escolheu-se a família Vochysiaceae por ser bem representada no cerradão (Faraco 2007) lá existente e possibilitar, dessa forma, a exemplificação de diversos aspectos do ensino de botânica durante aula prática de campo através dos seus indivíduos e espécies.

Segundo Warming \& Ferri (1973), as espécies de Vochysiaceae podem ser classificadas como as mais bonitas e mais representativas de cerrado. Neste sentido, pode-se destacar as inflorescências amarelas de Vochysia, as flores de Qualea com sua única pétala e um único estame, e os troncos tortuosos de Qualea grandiflora Mart. Tais aspectos podem ser evidenciados em aula prática de campo, como estimuladores e formadores de aspectos estéticos e éticos acerca daquela vegetação, necessários para o aluno formar valores que o conduzam a avaliar a real necessidade de preservação ou conservação destas espécies. Assim, para embasar a proposta da utilização desta família no desenvolvimento do projeto em que está inserido tornou-se importante responder as seguintes questões: Quais são as características estruturais predominantes nessa família? Quais relações ecológicas podem ser observadas e utilizadas como exemplos vivos nas aulas práticas de campo? Quais aspectos etnobotânicos são conhecidos a respeito das plantas dessa família?

Deste modo, foram descritas as espécies de Vochysiaceae identificadas em um fragmento de cerrado no campus de Bauru da UNESP, e organizadas tais informações de modo a oferecer um instrumento didático através de uma chave de identificação, um catálogo das espécies daquela família e um glossário simplificado dos termos utilizados.

\section{A família Vochysiaceae}

A família Vochysiaceae compreende cerca de 240 espécies e oito gêneros. São lenhosas, geralmente arbóreas, de folhas opostas ou verticiladas, simples, estípulas às vezes glandulares (Qualea), com flores períginas ou epíginas, diclamídeas ou monoclamídeas, frequentemente zigomorfas, isoladas ou em inflorescência do tipo tirso, cálice geralmente calcarado, corola frequentemente com número reduzido de pétalas e um único estame fértil, com frutos capsulares ou samaróides e sementes geralmente aladas (Barbosa 1999, Shimizu 2009). A família é dividida em duas tribos: Vochysieae Dumort. e Erismeae Dumort. A tribo Vochysieae, caracterizada por ovário súpero e trilocular, é composta por quatro gêneros: Callisthene Mart. (11 espécies), Qualea Aubl. (cerca de 50 espécies), Ruizterania Marc.Berti (14 espécies), Salvertia A.St.-Hil. (uma espécie) e Vochysia Aubl. (ca. 140 espécies) (G. Shimizu, dados não publicados). Erismeae possui ovário ínfero e unilocular e apresenta três gêneros: Erisma Rudge (16 espécies), Erismadelphus Mildbr. (duas espécies) e Korupodendron Litt \& Cheek (uma espécie). Marcano-Berti (1969) elevou Qualea seção Trichanthera ao gênero Ruizterania, mas estudos macromoleculares (Litt 1996) e anatômicos (Sajo \& Rudall 2002) não corroboraram essa separação. Em seu tratamento para a família, Kawasaki (2006) inclui Ruizterania em Qualea, porém sem sinonimizar formalmente as espécies de Ruizterania. Assim, os gêneros Ruizterania e Qualea, serão considerados separadamente no presente trabalho.

Salvo Ruizterania e Korupodendron, gênero monotípico descrito por Litt \& Cheek (2002), a composição da família acima apresentada é a comumente aceita pelos especialistas (Warming 1875, Stafleu 1948, 1952, 1953, 1954). 
As Vochysiaceae são plantas acumuladoras de alumínio, assim como as Rubiaceae, Melastomataceae, Proteaceae e Symplocaceae, e podem ocorrer em solos pobres em minerais e de baixo $\mathrm{pH}$, como os do Brasil Central (Haridasan 1982, Jansen et al. 2002). É uma família muito importante na caracterização de fitofisionomias, sendo considerada um componente típico nas comunidades vegetais de cerrado (Goodland 1971, Sarmiento 1983).

A distribuição da família é anfi-atlântica, predominantemente neotropical (seis dos oito gêneros), sendo apenas Erismadelphus e Korupodendron exclusivos do oeste e centro da África (Keay \& Stafleu 1953, Litt \& Cheek 2002, Senterre \& Obiang 2005). No Brasil, o núcleo de distribuição de suas espécies encontra-se na região Guiano-Amazônica e no Planalto Central Brasileiro, de onde se irradiam para as demais regiões (Barroso et al. 1984). No país, de acordo com a Lista de Espécies da Flora do Brasil (França 2012), ocorrem cerca de 160 espécies distribuídas em seis gêneros aceitos, constituindo uma das principais famílias do cerrado, onde se destacam principalmente os gêneros: Qualea, Vochysia, Callisthene e Salvertia.

Estudos sobre a biologia reprodutiva foram realizados para algumas espécies como Erisma uncinatum Warm. (Rodríguez \& Sanoja 2004), Qualea cordata Spreng. (Aveiro 1997, Fischer \& Gordo 1993), Qualea grandiflora Mart. (Barbosa 1983, Oliveira et al. 2004, Silberbauer-Gottsberger \& Gottsberger 1975), Qualea multiflora Mart. e Qualea parviflora Mart. (Barbosa 1983), Salvertia convallariodora A.St.-Hil. (Oliveira 1996), Vochysia cinnamomea Pohl (Santos et al. 1997), Vochysia elliptica Mart., Vochysia pumila Pohl, Vochysia pyramidalis Mart., Vochysia rufa Mart., Vochysia thyrsoidea Pohl e Vochysia tucanorum Mart. (Oliveira \& Gibbs 1994), Vochysia lucida C. Presl (Gimenes 2007), Vochysia ferruginea Mart. (Bawa et al. 1985, Flores 1993) e Vochysia guatemalensis Donn. Sm. (Flores 1993).

A maioria das espécies estudadas é melitófila, sendo Callisthene polinizada principalmente por abelhas pequenas e Qualea e Vochysia por abelhas grandes, tendo como polinizadores secundários e oportunistas esfingídeos e beija-flores (Gottsberger \& SilberbauerGottsberger 2006, Oliveira 1998). Já em Qualea grandiflora e Salvertia convallariodora a polinização é esfingófila (Oliveira 1998). Em Vochysia cinnamomea as flores são visitadas principalmente por abelhas do gênero Epicharis e outras Anthophoridae, que são os polinizadores principais, mas beija-flores e esfingídeos diurnos também são observados (Santos et al. 1997). Existem na literatura estudos para a família Vochysiaceae que apresentam listas e tratamentos taxonômicos muitas vezes com chaves dicotômicas para a identificação de gêneros e espécies nativas (Barbosa 1999, França 1996, Lisboa 2000, Shimizu 2009, Vianna 2006, Yamamoto 2009). No entanto, são inexistentes os que apresentaram tais resultados de maneira didática para um público não acadêmico, de modo a possibilitar o entendimento e o contato com os termos utilizados na nomenclatura botânica por alunos do ensino fundamental e médio.

\section{Considerações a respeito da ocorrência de espécies da família Vochysiaceae nos estudos de composição e estrutura de comunidades vegetais de matas e cerrados em Bauru}

\subsection{Nos remanescentes de Floresta Estacional Semidecidual}

Cavassan (1982) e Cavassan et al. (1984) apresentaram os resultados do levantamento fitossociológico da vegetação arbórea da mata da Reserva Estadual de Bauru e incluíram naquele levantamento a espécie Qualea jundiahy Warm. Tal espécie também foi a única pertencente à família Vochysiaceae amostrada por Toniato (2001), ao medir as variações na composição e estrutura da comunidade arbórea da mesma área em questão.

Pinheiro (2000) realizou um levantamento florístico e fitossociológico da Floresta Estacional Semidecidual do Jardim Botânico Municipal de Bauru (JBMB) (SP). Naquele estudo, amostrou as seguintes espécies de Vochysiaceae: Qualea cordata, Qualea grandiflora, Qualea multiflora, Vochysia cinnamomea e Vochysia tucanorum. A família possuiu grande número de indivíduos no interior das parcelas, sendo uma das famílias mais importantes da mata do JBMB e com maior riqueza de espécies. Vochysia tucanorum apresentou uma alta dominância relativa $(4,93 \%)$ e um grande valor de importância (VI) (6,92\%), em comparação com as outras espécies amostradas naquele estudo. A ocorrência de um número maior de espécies de Vochysiaceae nessa formação pode estar relacionada com a localização do fragmento estudado: uma área de transição com o cerrado.

\subsection{Em áreas de cerrado}

Os trabalhos realizados em fragmentos de cerrado amostraram as seguintes espécies de Vochysiaceae: Callisthene fasciculata, Qualea cordata, Qualea densiflora Warm., Qualea grandiflora, Qualea multiflora, Qualea parviflora, Qualea sp., Vochysia cinnamomea e Vochysia tucanorum (Cavassan 1990, Faraco 2007, Rissi 2011). De acordo com Cavassan (1990), a família Vochysiaceae foi a quarta família com o maior número de espécies $(5,32 \%)$, a terceira em relação ao valor de importância (VI) $(23,71 \%)$, a segunda em dominância $\left(7,6512 \mathrm{~m}^{2} / \mathrm{ha}\right)$ e a sétima em densidade absoluta. Vochysia tucanorum foi a oitava espécie mais numerosa (299 indivíduos), sétima em frequência absoluta, segunda em dominância absoluta $\left(5,1956 \mathrm{~m}^{2} /\right.$ ha) e quinta em VI $(20,29 \%)$. Qualea grandiflora foi a décima espécie neste mesmo índice $(8,64 \%)$. Segundo Faraco (2007), Vochysia tucanorum foi a espécie com maior valor de importância (VI) (10,59\%) fortemente influenciado pela sua dominância relativa $(19,39 \%)$.

Rissi (2011) apontou Vochysiaceae como a segunda família com o maior valor de importância (VI) em um fragmento de cerradão. A dominância relativa foi o parâmetro com maior contribuição para a constituição daquele índice. Como exemplo, pode-se citar a espécie Vochysia tucanorum que parece exercer um papel importante na composição estrutural da vegetação, sendo a espécie com maior VI (15,06\%), fortemente influenciado pela sua dominância relativa (37,35\%), sendo responsável por $82,88 \%$ deste índice.

\section{Material e Métodos}

\section{Caracterização da área de estudo: A Reserva Legal do Campus da UNESP}

O presente trabalho foi realizado em uma trilha localizada em fragmento da Reserva Legal do Campus de Bauru da UNESP. Esta Reserva fica compreendida entre as coordenadas, $22^{\circ} 20^{\prime} \mathrm{S}$ e $49^{\circ}$ $01^{\prime} \mathrm{W}$ e $22^{\circ} 21^{\prime} \mathrm{S}$ e $49^{\circ} 00^{\prime} \mathrm{W}$ com altitude aproximada de 580 m (Cavassan et al. 2006) e é revestida em toda sua extensão por vegetação nativa classificada como cerradão. Existem também na reserva, em dois vales, encravadas no cerrado, dois fragmentos de mata estacional semidecidual ribeirinha com encharcamento permanente (mata de brejo segundo Rodrigues \& Leitão-Filho 2000), onde ocorrem as nascentes do córrego Vargem Limpa, afluente da margem direita do rio Bauru, que por sua vez é tributário do rio Tietê (Cavassan et al. 2006). A classificação climática para Bauru é clima úmido e mesotérmico, com moderada eficiência da umidade no verão e marcha anual da temperatura concentrada em cerca de seis meses no ano (outubro-março), cuja fórmula climática de Thornwaite é representada por: BB'sb (Figueiredo \& Paz 2010) (Figura 1). A trilha 
Rissi, M.N. \& Cavassan, O.

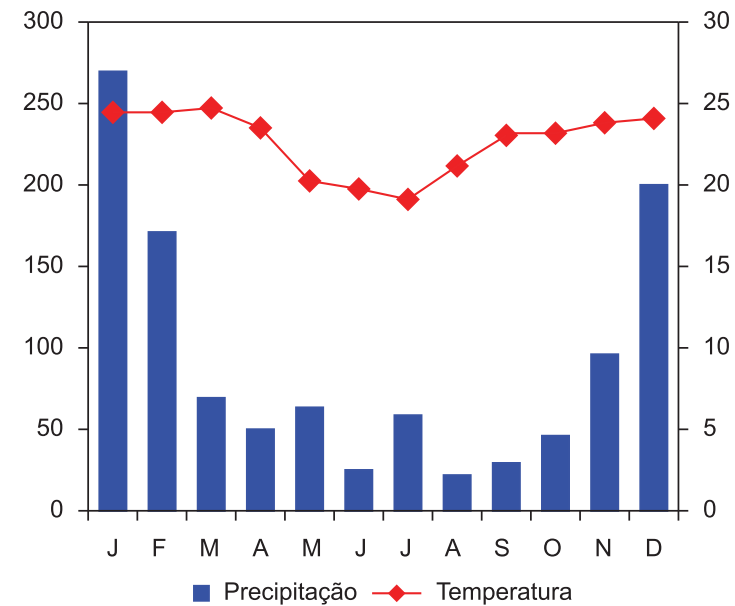

Figura 1. Climatograma da cidade de Bauru - SP, ano de 2008.

Figure 1. Climatogram of Bauru - SP, 2008.

utilizada para este estudo está localizada próxima aos pontos $22^{\circ} 21^{\prime}$ ' 19.15" S e $49^{\circ} 1^{\prime} 48.62^{\prime \prime}$ W e $22^{\circ} 21.18^{\prime} 77^{\prime}$ ' S e $49^{\circ} 01^{\prime} 41.11^{\prime \prime} \mathrm{W}$.

\section{Coleta de dados}

Para a condução do estudo foram descritas cinco plantas de cada uma das seis espécies que ocorreram ao longo da trilha utilizada para as aulas de campo. De cada indivíduo, foram coletados ramos férteis contendo estruturas vegetativas adequadas à descrição, que foram posteriormente herborizados e incorporados ao acervo do Herbário (UNBA) do Departamento de Ciências Biológicas da Faculdade de Ciências do Campus de Bauru da UNESP. A partir das espécies encontradas neste estudo, foi elaborada uma chave de identificação baseada preferencialmente em caracteres vegetativos.

Foram feitas fotografias do tronco, ramos e folhas de cada espécie, destacando-se as porções vegetativas de fundamental importância na identificação de cada espécie coletada, além das estruturas reprodutivas, quando presentes.

Um catálogo com a descrição morfológica, fotos e informações etnobotânicas foi elaborado como forma de sintetizar os dados taxonômicos, etnobotânicos e ecológicos das espécies e torná-los acessíveis para os alunos visitantes do projeto. Um glossário também foi desenvolvido como facilitador para o entendimento dos termos apresentados no catálogo e na chave. Os dados ecológicos, relativos à polinização e à dispersão, foram obtidos através da observação em campo e complementados através da literatura. Para caracterização das interações ecológicas utilizaram-se dados disponíveis na literatura específica (Bentley \& Elias 1983, Oliveira et al. 1987, Begon et al. 1996, Madureira \& Sobrinho 2002, Knoechelmann \& Morais 2008) bem como para as informações etnobotânicas (Rodrigues \& Carvalho 2001, Vila Verde et al. 2003, Gorette-Pasa 2011) e os dados complementados por observações esporádicas de campo.

Cabe ressaltar que a intenção do levantamento dos aspectos etnobotânicos visa uma complementação dos dados levantados neste trabalho. As informações referentes ao uso na medicina popular foram abordadas durante as atividades práticas de campo, apenas através da citação que determinada espécie possui potencial farmacológico, omitindo-se qualquer menção à posologia, indicação ou parte da planta utilizada. Dessa forma, chama-se a atenção da potencialidade de espécies nativas na farmacopéia brasileira, mas procura-se não incentivar o uso destas plantas como medicação sem orientação médica.
O glossário foi elaborado e adaptado a partir dos conceitos obtidos nas seguintes obras: Ferri et al. (1969), Souza \& Lorenzi (2008) e Raven et al. (2010).

\section{Resultados e Discussão}

O ensino convencional de botânica apresenta uma aula dita teórica, na qual o aluno geralmente ouve e memoriza um conjunto de informações como sendo os conteúdos mais importantes, mesmo que estes, muitas vezes, não estejam inseridos em sua realidade. Essa passividade dos alunos é uma desvantagem das aulas expositivas, pois pouca informação é retida devido ao decréscimo da atenção no decorrer da aula. Por isso, existe a necessidade de se encontrarem formas alternativas de trabalho que permitam a manutenção da atenção dos alunos durante todo o período de aula. Para isso, é necessário instigar intelectualmente os alunos, através de discussões e estímulos sensoriais. Os conceitos, quando apresentados por meio de uma discussão ficam mais inteligíveis e as aulas se tornam mais agradáveis e interessantes, além de desafiarem a imaginação e vivacidade dos estudantes. $\mathrm{O}$ uso de exemplos adequados durante a aula é importante não só para motivar os alunos, mas para ajudá-los a entender idéias abstratas e aproximar os conteúdos da realidade do aluno. Os exemplos servem para ilustrar uma idéia ou para verificar se os alunos entenderam um conceito (Krasilchik 1996). Pode-se dizer que uma grande parte dos livros didáticos brasileiros utilizados até hoje se vale da taxonomia para apresentar ao estudante de Ensino Médio uma botânica “decorativa”. Os alunos são entregues a uma verdadeira avalanche de nomes e estruturas, muitas vezes sem contexto e significado tangíveis (Marcondes \& Lammoglia 1994, Fonseca 1995).

Segundo Santiago dos Santos (2006), a visão estática da Botânica deveria ser substituída por uma didática na qual os conceitos básicos possam ser ressaltados no sentido de permitir a interpretação dos fatos, ao invés de apenas memorizá-los. Deste modo, o educando é estimulado a exercitar seu espírito de observação, passando a ser um ordenador e sintetizador de informações. Joly (1976) recomenda que o professor jamais tente desenvolver o estudo da classificação das plantas sem recorrer a exemplares vivos, isto é, à natureza. Em hipótese alguma os ensinamentos teóricos indispensáveis devem ser ministrados sem a correspondente aula prática, pois, para o autor só esta pode levar o aluno a fixar as características mais importantes de cada grupo. De acordo com Seniciato \& Cavassan (2008a), em termos de estratégias de ensino de ciências, as aulas práticas são apontadas como mais interessantes e motivadoras, quando comparadas às tradicionais aulas teóricas, principalmente por incluírem os fenômenos nos contextos de aprendizagem.

Piaget (1996) reafirma que o conhecimento é baseado, sobretudo, na experimentação. Dessa forma, os processos de assimilação da realidade serão tanto mais afetivos quanto mais tangíveis e palpáveis forem de fato, ou seja, as capacidades de abstração e de conceituação são facilitadas quando o aprendiz estiver exposto à dimensão concreta da realidade (Seniciato \& Cavassan 2008a). A atividade de campo pode assim aguçar a percepção, o senso estético e a curiosidade do aluno em relação aos fenômenos apresentados, motivando-o para o aprendizado na escola, e a buscar mais informações por conta própria (Ikemoto 2007).

Neste sentido, as informações levantadas ao longo deste estudo buscaram aproximar o aluno da realidade em que vive fazendo com que este pudesse visualizar, refletir e compreender os temas apresentados em sala de aula através de exemplos vivos em aula de campo ou visualizados no catálogo de espécies. Foram amostradas e descritas as espécies Qualea cordata, Qualea grandiflora, Qualea multiflora, Qualea parviflora, Vochysia cinnamomea e Vochysia tucanorum (Tabela 1). O catálogo de espécies, a chave de identificação 
Tabela 1. Espécies da família Vochysiaceae amostradas neste estudo, nomes científicos, nomes populares, hábito e número de registro no Herbário da UNESP de Bauru (UNBA).

Table 1. Family Vochysiaceae species sampled in this study, scientific names, common names, habit and registration number in the Herbarium of UNESP of Bauru (UNBA).

\begin{tabular}{llll}
\hline \multicolumn{1}{c}{ Espécie } & \multicolumn{1}{c}{ Nome popular } & Hábito & $\begin{array}{c}\text { Número de registro no } \\
\text { Herbário UNBA }\end{array}$ \\
\hline Qualea cordata Spreng. & pau-terra, carvãozinho, dedaleira-preta & Arbóreo & $5243,5026,5028,5030,5035$. \\
Qualea grandiflora Mart. & pau-terra, pau-terra-do-campo, pau-terra-de-folha-grande & Arbóreo & $4089,4097,5011,5024,5025$. \\
Qualea multiflora Mart. & cinzeiro, pau-terra-do-campo, pau-terra-de-casca-lisa & Arbóreo & $4095,5010,5023,5027,5029$. \\
Qualea parviflora Mart. & pau-terra, pau-terra-de-folha-miuda & Arbóreo & $3870,4088,4090,4091,4093$. \\
Vochysia tucanorum Mart. & cinzeiro, pau-de-tucano & Arbóreo & $4092,4096,4098,5000,5012$. \\
Vochysia cinnamomea Pohl & casca-doce, quina-doce, pau-doce & Arbóreo & $5021,5022,5206,5207,5208$. \\
\hline
\end{tabular}

e o glossário com os termos utilizados, foram construídos como ferramentas auxiliares para a condução destes estudos práticos. No catálogo, as pranchas para cada espécie abordam, em sentido antihorário, fotos do hábito, caule, folhas, flores e frutos. Nas pranchas 4 e 5 , a sequência de fotos inclui fotos de polinizadores.

A proposta é a de que os professores possam se utilizar da chave e do catálogo de espécies para o ensino de Sistemática Vegetal, botânica e ecologia. O glossário visa solucionar dúvidas sobre o significado dos termos botânicos utilizados na chave e no catálogo.

Os dados apresentados devem ser trabalhados através de uma didática motivadora, fazendo com que, através da visualização, investigação e problematização do fenômeno apontado, o aluno possa construir o seu conceito através da elaboração de hipóteses, tornando-se assim, um agente construtor do conhecimento. Além disso, a formulação desses conceitos por parte do próprio educando pode servir de ponto de partida para discussões interessantes e aprofundadas, comparando seus conceitos a outros já existentes.

Um exemplo desta abordagem é a presença de nectários extraflorais na base do pecíolo das espécies do gênero Qualea. Esse caráter permite a identificação deste gênero, além de ilustrar um exemplo de interação ecológica. Em uma aula essa característica poderia ser abordada através de algumas perguntas: "Vocês estão visualizando essa glândula e essa formiga? O que é uma glândula? Que fenômeno estamos observando? Por que será que essa formiga está nesta glândula?”. Através de algumas perguntas busca-se direcionar o pensamento e as reflexões dos alunos, mas deve-se estar atento para não responder às questões. Deve-se deixá-los discutir sobre tais questões que serão abordadas ao final da atividade. Dessa forma, os alunos podem formular hipóteses e discuti-las, ao invés de receberem todos os conceitos prontos. Outras informações obtidas neste estudo podem ser trabalhadas através da formulação de hipóteses como, por exemplo: “As espécies de Vochysiaceae são plantas acumuladoras de alumínio." Trabalhando tais informações, os alunos podem chegar à conclusão de que "Os solos com maior concentração de alumínio tendem a ser povoados por plantas que têm a capacidade de acumular alumínio".

Assim, as espécies de Vochysiaceae podem servir como exemplosvivos de diversos fenômenos e, por possuírem características típicas de espécies de cerrado, podem ainda servir como elementos motivadores e com apelo estético para o aprendizado sobre as características desta vegetação. Na paisagem do Cerrado são comumente encontradas árvores tortuosas e suberosas, características estas notórias em espécies de Vochysiaceae.

Aos professores que queiram trabalhar o tema "interações ecológicas", alguns exemplos que ocorrem com espécies da família Vochysiaceae estão relacionados no catálogo. As fotos contidas no catálogo ilustram tais interações e, juntamente com as explicações, permitem que os alunos conheçam um pouco mais sobre o ambiente do Cerrado.

De acordo com Dewey (1938), "os alunos aprendem fazendo". Essa educação se dá através da experiência. Se uma experiência for desarticulada, desprovida de atenção e reflexão, essa atitude irá operar modificando a qualidade das experiências subsequentes, não permitindo aos alunos retirar delas o que deveriam. Uma boa experiência, mais que imediatamente agradável, promove o desencadeamento de experiências futuras positivas. Nesse sentido, o material elaborado busca aproximar o educando dos temas apresentados em sala de aula, através do entendimento e reflexão sobre os temas abordados e uma boa experiência reflexiva sobre seus conteúdos.

Uma metodologia diferenciada no ensino de botânica, segundo Pinheiro da Silva (2008), pode fomentar uma atitude reflexiva por parte do aluno, na medida em que oferece a este, oportunidades de participação, nas quais vivencie uma variedade de experiências, seja solicitado a tomar decisões, fazer julgamentos e chegar a conclusões.

\section{Agradecimentos}

À FAPESP pela bolsa de Iniciação Científica concedida processo: 2008/50615-3.

À Profa. Dra. Kikyo Yamamoto, do Departamento de Biologia Vegetal, Instituto de Biologia da Universidade Estadual de Campinas, pela confirmação das espécies descritas neste estudo.

Ao taxonomista Doutorando Gustavo Shimizu pela ajuda com a revisão do texto e das informações contidas neste documento.

Ao tradutor Rodrigo Guimarães e ao Prof. Dr. Reinaldo Monteiro pela revisão dos textos em inglês.

\section{Referências Bibliográficas}

AVEIRO, S.M.G. 1997. Biologia da reprodução e crescimento inicial de Qualea cordata Spreng. (Vochysiaceae), uma espécie arbórea do Cerrado. Tese de Doutorado, Universidade Estadual de Campinas, Campinas. http://www.bibliotecadigital.unicamp.br/document/?code=vtls000121 $464 \& \mathrm{fd}=\mathrm{y}$

BARBOSA, A.A.A. 1983. Aspectos da ecologia reprodutiva de três espécies de Qualea (Vochysiaceae) num cerrado de Brasília-DF. Dissertação de Mestrado, Universidade de Brasília, Brasília. http://pesquisa.bvsalud.org/ regional/resources/rep-131156

BARBOSA, A.R. 1999. As espécies do gênero Vochysia Aubl. (Vochysiaceae) ocorrentes no Estado de São Paulo. Tese de Mestrado, Universidade Estadual de Campinas, Campinas. http://www.bibliotecadigital.unicamp. $\mathrm{br} /$ document $/$ ?code $=$ vtls000199970

BARROSO, G.M., PEIXOTO, A.L., ICHASO, C.L.F., GUIMARÃES, E.F. \& COSTA, C.G. 1984. Sistemática de Angiospermas do Brasil. UFV, Impr. Univ., Viçosa, v.2. 
BAWA, K.S., PERRY, D.R. \& BEACH, J.H. 1985. Reproductive biology of tropical lowland rain forest trees. I. Sexual systems and incompatibility mechanisms. Am. J. Bot. 72:331-345. http://dx.doi.org/10.2307/2443526

BEGON, M., HARPER, J.L. \& TOWNSEND, C.R. 1996. Ecology: individuals, populations and communities. Blackwell Science, Victoria.

BENTLEY, B. \& ELIAS, T.S. 1983. The biology of nectaries. Columbia University Press, New York.

CAVASSAN, O. 1982. Levantamento florístico da vegetação arbórea da mata da Reserva Estadual de Bauru utilizando o método de quadrantes. Dissertação de Mestrado, Universidade Estadual Paulista, Rio Claro.

CAVASSAN, O., CESAR, O. \& MARTINS, F.R. 1984. Fitossociologia da vegetação arbórea da Reserva Estadual de Bauru, Estado de São Paulo. Rev. Bras. Bot. 7:91-106.

CAVASSAN, O. 1990. Florística e fitossociologia da vegetação lenhosa de um hectare de cerrado do Parque Ecológico Municipal de Bauru (SP). Tese de Doutorado, Universidade Estadual de Campinas, Campinas. http:// www.bibliotecadigital.unicamp.br/document/?code=vtls000036013.

CAVASSAN, O., PINHEIRO DA SILVA, P.G. \& SENICIATO, T. 2006. O ensino de Ciências, a biodiversidade e o Cerrado. In Divulgação Científica e Ensino de Ciências: Estudos e Experiências (E.S.N.N. de Araújo, J.J. Caluzi, A.M.A. Caldeira, eds.). Escrituras, São Paulo, p.190-219.

CAVASSAN, O., CALDEIRA, A.M.A., WEISER, V.L. \& BRANDO, F.C. 2009. Conhecendo botânica e ecologia no Cerrado. Joarte Gráfica e Editora, Bauru.

DEWEY, J. 1938. Experience and Education. The $60^{\text {th }}$ anniversary edition. http://books.google.com/books?hl=pt-BR\&lr=\&id=UE2EusaU53IC\&o $\mathrm{i}=$ fnd\&pg $=$ PR $4 \& \mathrm{dq}=$ Dewey\&ots=EDZZ3nPXLk\&sig=spiXEDMvSR Jaz59TAHQKuV_0Y8w\#PPP1,M1.

DEWEY, J. 1959. Como pensamos. Editora Nacional, São Paulo.

FARACO, A.G. 2007. Composição florística e estrutura fitossociológica de uma área de cerrado pertencente ao Campus de Bauru da Universidade Estadual Paulista - UNESP, SP. Dissertação de Mestrado, Universidade Estadual Paulista, Botucatu.

FERRI, M.G., MENEZES, N.L. \& MONTEIRO-SCANAVACCA, W.R. 1969. Glossário de termos botânicos. Editora Edgard Blücher Ltda, São Paulo.

FIGUEIREDO, J.C. \& PAZ, R.S. 2010. Nova classificação climática e o aspecto climatológico da cidade de Bauru/São Paulo. In: XVI Congresso Brasileiro de Meteorologia. Sociedade Brasileira de Agrometeorologia.

FISCHER, E.A. \& GORDO, M. 1993. Qualea cordata, pollination by the territorial bee Centris tarsata in the "Campos Rupestres", Brazil. Cienc. Cult. 45:144-147.

FLORES, E.M. 1993. Vochysia guatemalensis y Vochysia ferruginea. Árboles Semillas Neotrop. 2:1-52.

FONSECA, A. 1995. Biologia. Ática, São Paulo.

FRANÇA, F. 1996. O gênero Callisthene Mart. \& Zucc. (Vochysiaceae) no estado da Bahia. Sitientibus 15:41-47.

FRANÇA, F. 2012. Vochysiaceae. In Lista de Espécies da Flora do Brasil. Jardim Botânico do Rio de Janeiro. http://floradobrasil.jbrj.gov.br/2012/ FB000250

GIMENES, M. 2007. Polinização de Vochysia lucida C. Presl (Vochysiaceae) em uma área de restinga na Bahia. Rev. Bras. Ento. 51(4):465-470. http:// dx.doi.org/10.1590/S0085-56262007000400010

GOODLAND, R. 1971. A physiognomic analysis of the cerrado vegetation of Central Brazil. J. Ecol. 59:411-419. http://dx.doi.org/10.2307/2258321

GORETTE-PASA, M. 2011. Abordagem etnobotânica na comunidade de Conceição-Açu, Mato Grosso, Brazil. Polibotânica 31:169-197.

GOTTSBERGER, G. \& SILBERBAUER-GOTTSBERGER, I. 2006. Life in the Cerrado: a South American tropical seasonal vegetation. Pollination and seed dispersion. Reta Verlag, Ulm.

HARIDASAN, M. 1982. Aluminium accumulation by some cerrado native species of central Brazil. Plant Soil. 65(2):265-273. http://dx.doi. org/10.1007/BF02374657
IKEMOTO, E. 2007. Espécies arbóreas, arbustivas e herbáceas do Parque Taquaral (Campinas, SP) - subsídios para a atividade não formal de botânica. Dissertação de mestrado, Universidade Estadual de Campinas, Campinas. http://www.bibliotecadigital.unicamp.br/document/?code=vt ls $000412927 \&$ fd $=y$

JANSEN, S., BROADLEY, M.R., ROBBRECHT, E. \& SMETS, E. 2002. Aluminium hyperaccumulation in angiosperm: a review of its phylogenetic significance. The Bot. Rev. 68(2):235-269. http://dx.doi. org/10.1663/0006-8101(2002)068[0235:AHIAAR]2.0.CO;2

JOLY, A.B. 1976. Botânica: introdução à taxonomia vegetal. Nacional, São Paulo.

KAWASAKI, M.L. 2006. Vochysiaceae. In The families and genera of vascular plants (K. Kubitzki, ed.). Springer, Berlin, p.480-487.

KEAY, R.W.J. \& STAFLEU, F.A. 1953. Erismadelphus. Acta Bot. Neerl. 1:594-599.

KNOECHELMANN, C.M. \& MORAIS, H.C. 2008. Visitas de formigas (Hymenoptera, Formicidae) a nectários extra-florais de Stryphnodendron adstringens (Mart.) Cov. (Fabaceae, Mimosoideae) em uma área de cerrado frequentemente queimado. Rev. Bras. Zooc. 10(1):35-40.

KRASILCHIK, M. 1996. Prática de Ensino de Biologia. Harbra, São Paulo.

LISBOA, M.L.G. 2000. Estudos taxonômicos sobre o gênero Qualea Aubl., subgênero Amphilochia (Mart.) Stafl. (Vochysiaceae A. St.-Hil.). Dissertação de Mestrado. Universidade Estadual de Campinas, Campinas. http://www.bibliotecadigital.unicamp.br/document/?code=vtls000205 968\&opt $=1$

LITT, A. 1996. Phylogeny of the Vochysiaceae: implications of molecular data for floral evolution. Am. J. Bot. 83(abstracts): 175 .

LITT, A. \& CHEEK, M. 2002. Korupodendron songweanum, a new genus and species of Vochysiaceae from West-Central Africa. Brittonia 54:13-17. http://dx.doi.org/10.1663/0007-196X(2002)054[0013:KSANGA]2.0. $\mathrm{CO} ; 2$

MADUREIRA, M. \& SOBRINHO, T.G. 2002. Evidência de mutualismo entre Qualea cordata (Vochysiaceae) e Cephalotes sp. (Hymenoptera: Formicidade). Acad. Insecta 2(1):1-4.

MARCANO-BERTI, L. 1969. Un nuevo genero de las Vochysiaceae. Pittieria 2:3-28.

MARCONDES, A.C. \& LAMMOGLIA, D.A. 1994. Biologia - ciência da vida. Atual, São Paulo.

OLIVEIRA, P.S., SILVA, A.F. \& MARTINS, A.B. 1987. Ant foraging on extrafloral nectaries of Qualea grandiflora (Vochysiaceae) in cerrado vegetation: ants as potencial antiherbivore agents. Oecologia 74:228-230. http://dx.doi.org/10.1007/BF00379363

OLIVEIRA, P.E. 1996. Biologia floral de Salvertia convallariodora (Vochysiaceae): uma espécie de cerrado polinizada por mariposas. Rev. Bras. Bot. 19(1):49-53.

OLIVEIRA, P.E. 1998. Reproductive biology, evolution and taxonomy of Vochysiaceae in central Brazil. In Reproductive Biology (S.J. Owens \& P.J. Rudall, eds.). Kew, Royal Botanic Gardens, London, p.381-393.

OLIVEIRA, P.E. \& GIBBS, P.E. 1994. Pollination and breeding systems of six Vochysia species (Vochysiaceae). J. Trop. Ecol. 10:509-522. http:// dx.doi.org/10.1017/S026646740000818X

OLIVEIRA, P.E., GIBBS, P.E. \& BARBOSA, A.A. 2004. Moth pollination of woody species in the Cerrados of Central Brazil: a case of so much owed to so few? Plant Syst. Evol. 245:41-54. http://dx.doi.org/10.1007/ s00606-003-0120-0

PIAGET, J. 1996. Biologia e conhecimento - ensaio sobre as relações entre as regulações orgânicas e os processos cognoscitivos. Vozes, Petrópolis.

PINHEIRO DA SILVA, P.G. 2008. O Ensino da Botânica no Nível Fundamental: um enfoque nos procedimentos metodológicos. Tese de Doutorado, Universidade Estadual Paulista, Bauru. http://www2.fc.unesp. br/BibliotecaVirtual/ArquivosPDF/TES_DOUT/TES_DOUT20080328 SILVA\%20PATRICIA\%20GOMES\%20PINHEIRO\%20DA.pdf. 
PINHEIRO DA SILVA, P.G., CAVASSAN, O. \& SENICIATO, T. 2009. Os ambientes naturais e a didática das ciências biológicas. In Educação para a ciência: introdução à didática da biologia (A.M.A Caldeira \& E.S.N.N . de Araújo, eds.). Escrituras, São Paulo, v.10, p.289-303.

PINHEIRO, M.H.O. 2000. Levantamento florístico e fitossociológico da floresta estacional semidecidual do Jardim Botânico Municipal de Bauru, São Paulo. Tese de Doutorado, Universidade Estadual de Campinas, Campinas. http://www.bibliotecadigital.unicamp.br/ document/?code=vtls000211351

RAVEN, P. H., EVERT, R. F. \& EICHHORN, S. E. 2010. Biologia Vegetal. Guanabara Koogan, Rio de Janeiro.

RISSI, M.N. 2011. Regeneração natural de um fragmento de cerrado degradado com a formação de pastagens de braquiária (Urochloa decumbens (Stapf) R.D.Webster). Dissertação de Mestrado, Universidade Estadual Paulista, Botucatu. http://www2.ibb.unesp.br/posgrad/teses/ botanica_me_2011_mariana_rissi_corrigida.pdf.

RODRÍGUEZ R.L. \& SANOJA, E. 2004. Aspectos de la biología reproductiva de Erisma uncinatum Warm., (Vochysiaceae), la primera especie maderable del Estado Bolívar, Venezuela. Acta Bot. Ven. 27(1):23-33.

RODRIGUES, R.R. \& LEITÃO-FILHO, H.F. 2000. Matas ciliares: conservação e recuperação. EdUSP, FAPESP, São Paulo.

RODRIGUES, V.E.G. \& CARVALHO, D.A. 2001. Levantamento etnobotânico de plantas medicinais no domínio cerrado na região do alto Rio Grande - Minas Gerais. Cienc. Agrotec. 25(1):102-123.

SAJO, M.G. \& RUDALL, P.J. 2002. Leaf and stem anatomy of Vochysiaceae in relation to subfamilial and suprafamilial systematics. Bot. J. Linn. Soc. 138: 339-364. http://dx.doi.org/10.1046/j.1095-8339.2002.00025.x

SANTIAGO DOS SANTOS, F. 2006. A botânica no Ensino Médio: Será que é preciso apenas memorizar nomes de plantas?. In Estudos de história e filosofia das ciências: subsídios para aplicação no ensino (C.B. Silva, org.). Editora Livraria da Física, São Paulo, p.223-243.

SANTOS, M.L., AFONSO, A.P. \& OLIVEIRA, P.E. 1997. Biologia floral de Vochysia cinnamomea Pohl (Vochysiaceae) em cerrados do Triângulo Mineiro, MG. Rev. Bras.Bot. 20(2):127-132. http://dx.doi.org/10.1590/ S0100-84041997000200003

SARMIENTO, G. 1983. The savannas of tropical America. In Ecosystems of the world: tropical savannas. (F. Bouliere, ed.). Elsevier, Amsterdam, p.245-288.

SENICIATO, T., PINHEIRO DA SILVA, P.G. \& CAVASSAN, O. 2006. Construindo valores estéticos nas aulas de ciências desenvolvidas em ambientes naturais. Ensaio 8(2):97-110.

SENICIATO, T. \& CAVASSAN, O. 2008a. Afetividade, motivação e construção de conhecimento científico nas aulas desenvolvidas em ambientes naturais. Ciênc. Cognição (UFRJ). 13(3):120-136.
SENICIATO, T. \& CAVASSAN, O. 2008b. A formação de conceitos científicos em aulas de campo: as possibilidades de aprendizagem segundo Piaget e Vigotski. In Educação para a ciência: práticas integradas para o ensino de biologia (E.S.N.N. de Araújo, J.J. Caluzi \& A.M.A. Caldeira, eds.) Escrituras, São Paulo, p.189-203.

SENICIATO, T. \& CAVASSAN, O. 2009. O ensino de ecologia e a experiência estética no ambiente natural: considerações preliminares. Ciênc. Educ. 15(2):393-412.

SENTERRE, B. \& OBIANG, D. 2005. Nouvelles découvertes à propos des Vochysiaceae africaines: Erismadelphus Mildbr. et Korupodendron Litt \& Cheek. Taxonomania. 17:3-18.

SHIMIZU, G.H. 2009. Vochysiaceae na Serra do Cipó, Minas Gerais, Brasil. Tese de Doutorado, Universidade Estadual de Campinas, Campinas. http://www.bibliotecadigital.unicamp.br/document/?code=000471952

SILBERBAUER-GOTTSBERGER, I. \& GOTTSBERGER, G. 1975. Über sphingophile Angiospermen Brasiliens. Plant Syst. Evol. 123:157-184. http://dx.doi.org/10.1007/BF00989402

SOUZA, V.C. \& LORENZI, H. 2008. Botânica sistemática. Guia ilustrado para identificação das famílias de Angiospermas da flora brasileira, baseado em APG II. Instituto Plantarum, Nova Odessa.

STAFLEU, F.A. 1948. A monograph of the Vochysiaceae I. Salvertia and Vochysia. Rec. Trav. Bot. Néerl. 41:397-540.

STAFLEU, F.A. 1952. A monograph of Vochysiaceae. II. Callisthene. Acta Bot. Neer. 1:222-242.

STAFLEU, F.A. 1953. A monograph of Vochysiaceae. III. Qualea. Acta Bot. Neer. 2:144-217.

STAFLEU, F.A. 1954. A monograph of Vochysiaceae. IV. Erisma. Acta Bot. Neer. 3:459-480.

TONIATO, M.T.Z. 2001. Variações na composição e estrutura da comunidade arbórea de um fragmento de floresta semidecidual em Bauru (SP), relacionadas a diferentes históricos de perturbações antrópicas. Tese de doutorado, Universidade Estadual de Campinas, Campinas. http://www. bibliotecadigital.unicamp.br/document/?code=vtls000236680

VIANNA, M.C. 2006. Vochysiaceae na Reserva Biológica de Poço das Antas, Silva Jardim, Rio de janeiro, Brasil. Rodriguésia 57(3):659-666.

VILA VERDE, G.M., PAULA, J.R. \& CANEIRO, D.M. 2003. Levantamento etnobotânico das plantas medicinais do cerrado utilizadas pela população de Mossâmedes - GO. Rev. Bras. Farmacogn. 13:64-66. http://dx.doi. org $/ 10.1590 /$ S0102-695X2003000300024

YAMAMOTO, K. 2009. Flora de Grão-Mogol, Minas Gerais: Vochysiaceae. Bol. Bot. Univ. São Paulo 27(1):131-136.

WARMING, E. 1875. Vochysiaceae. In Flora Brasiliensis (C.F.P. Martius, ed.). R. Oldenburg, Monachii, v.13, p.17-116.

WARMING, E. \& FERRI, M.G. 1973. Lagoa Santa e a vegetação de cerrados brasileiros. Itatiaia, Belo Horizonte, Universidade de São Paulo, São Paulo. 


\section{ANEXOS}

\section{Chave de identificação}

1 Glândulas (nectários extra-florais) abaixo do pecíolo, presença de nervura ao longo da margem da folha (nervuras coletoras)...........2

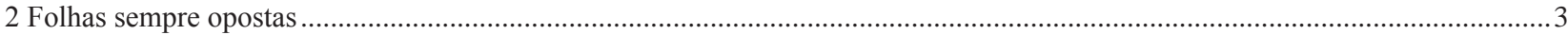

3 Casca descamante em placas nos ramos, folhas com mais de $8 \mathrm{~cm}$ compr., pétala glabra...............................Qualea grandiflora (pau-terra-de-folha-grande - prancha 2)

3' Casca não descamante em placas nos ramos, folhas menores que $8 \mathrm{~cm}$, pétala serícea na face adaxial ...............Qualea cordata (carvãozinho, dedaleira - prancha 1)

2' Folhas opostas ou verticiladas . .4 4 Caule fendilhado, pétala violácea, cápsula com superfície descamante .... Qualea parviflora (pau-terra-de-folha-miúda - prancha 4)

4' Caule com fissuras horizontais e aspecto liso, pétala não violácea, cápsula sem superfície descamante, (pau-terra-de-casca-lisa - prancha 3)

1' Glândulas (nectários extra-florais) abaixo do pecíolo ausentes, sem nervura ao longo da margem da folha (nervuras coletoras) ........5 5 Tronco suberoso sem cristas irregulares, indumento presente nas folhas Vochysia cinnamomea (pau-doce - prancha 5).

5' Tronco suberoso com cristas irregulares, indumento ausente nas folhas Vochysia tucanorum (pau-de-tucano - prancha 6).

\section{Glossário com os termos utilizados na chave de identificação e no catálogo de espécies.}

3-valvar: com três valvas.

Abaxial: refere-se à face inferior da folha.

Acuminado: ápice que se afunila formando uma projeção.

Adaxial: refere-se à face superior da folha.

Aguda (ápice/base): define a folha cujas margens aproximam-se entre si em um ângulo menor que $90^{\circ}$.

Ala lateral (semente): é a projeção lateral achatada e usualmente delgada, assemelhando-se a uma asa, que torna as sementes capazes de planar a pequenas distâncias.

Anemocórica: dispersão que tem como agente dispersor o vento.

Angiosperma: grupo de plantas que têm as sementes formadas dentro de um fruto.

Ápice: topo ou parte mais alta, na folha designa a porção oposta em relação ao pecíolo.

Arredondada (ápice/base): diz-se da parte da folha que possui formato de semi-círculo.

Base: porção oposta ao ápice.

Cano-pubescente: superfície coberta de pelos curtos, densos e acinzentados.

Cápsula: fruto seco, deiscente, que se desenvolve de dois ou mais carpelos desde que estejam fundidos.

Cartácea: denomina as folhas que possuem consistência de cartolina ou pergaminho.

Câmbio vascular: bainha cilíndrica de células meristemáticas, cujas divisões produzem floema secundário e xilema secundário.

Caule: é o eixo principal da planta, sendo dividido em nós e entrenós.

Células meristemáticas: células responsáveis principalmente pela formação de novas células.

Coletoras (nervuras): denominação dada à nervura marginal da borda da folha, na qual todas as nervuras secundárias desembocam.

Concolores: estruturas que possuem ambas as faces com a mesma coloração.

Cordada: que possui a forma aproximada de um coração. Base cordada se refere à base reentrante com os lobos arredondados.

Coriácea: denomina as folhas que possuem consistência endurecida, semelhante a couro.

Corola: conjunto de pétalas.

Crescimento secundário: em plantas, o crescimento derivado de meristemas secundários ou laterais, ou seja, do câmbio vascular e do felogênio. O crescimento secundário resulta em um aumento de espessura.

Cristas: saliências ou apêndices irregulares de alguns órgãos.

Cuneada: em forma de cunha.

Curto-pecioladas: folhas que possuem o pecíolo de tamanho diminuto, pequeno.

Descamante: que se esfolia em lâminas delgadas.

Deiscente: estrutura que se abre de forma espontânea na maturação.

Discolores: estruturas que possuem as faces com colorações distintas.

Dística: tipo de filotaxia onde as folhas estão dispostas em um único plano.

Esfoliante: tem o mesmo sentido que descamante.

Entomofilia: polinização que tem como agentes polinizadores insetos.

Epiderme: camada celular que reveste externamente as folhas, os caules e as raízes.

Esfingídeos: que pertencem à família Sphingidae, de mariposas grandes.

Etnobotânica: ramo da botânica que estuda o papel tradicional de certas plantas na vida e folclore de determinado povo.

Feloderme: tecido formado pelo felogênio para dentro, oposto ao súber, parte interna da epiderme.

Felogênio: o meristema lateral da planta que forma a periderme, produzindo o súber para fora (em direção à superfície) e a feloderme para dentro; é comum em caules e raízes de gimnospermas e angiospermas lenhosas.

Fendilhado: que possui fendas. 
Fenol: função orgânica caracterizada por uma ou mais hidroxilas ligadas a um anel aromático.

Fenólicos: que contem fenol.

Ferrugínea: designa qualquer parte do vegetal que possua coloração castanho-avermelhada, semelhante à ferrugem.

Filotaxia: denominação dada ao arranjo das folhas nos nós ao longo do eixo caulinar.

Floema: Tecido condutor de seiva elaborada das plantas vasculares.

Flor: órgão de reprodução sexuada das angiospermas.

Folha: estrutura aérea, com função principal de órgão fotossintético.

Fruto loculicida: cápsula que se abre no meio do lóculo.

Fruto: estrutura formada pelo desenvolvimento do ovário após a fertilização.

Gimnosperma: planta que produz sementes não encerradas em um ovário, as coníferas são um representante desse grupo.

Glabra: superfície sem pelos (tricomas).

Glabrescente: que se torna glabro, ou quase, com a maturação.

Hábito: forma geral de uma planta, sendo os principais tipos: erva trepadeira, liana, subarbusto, arbusto e arvóre.

Indumento: conjunto de pelos, escamas ou glândulas que cobre a superfície de um órgão.

Inflorescência: nome dado ao eixo caulinar que produz flores ao longo do seu comprimento.

Lenho: conjunto de elementos condutores lignificados e outros tecidos que compõem o xilema.

Lenhoso: referente ao lenho ou de natureza do lenho.

Lignificado: parte da planta que se impregna de lignina e que, em consequência, adquire consistência de madeira.

Lignina: substância que impregna a parede celulósica em certos tecidos. Principal componente da madeira, sendo responsável por sua resistência.

Lustrosa: denomina a superfície que possui aparência brilhante.

Margem (folha): Contorno ou bordo dos órgãos laminares ou comprimidos.

Meristema: a região com tecido embrionário, responsável principalmente pela formação de novas células.

Nectário: glândula ou tricoma que secreta néctar, podendo estar localizado na flor (floral) ou fora dela (nectário extra-floral).

Nervuras: elemento condutor, geralmente visível no limbo das folhas. Dividem-se em principal, secundária e terciária.

Nervuras coletoras: denominação dada à nervura marginal da borda da folha, na qual todas as nervuras secundárias desembocam.

Nervura marginal: refere-se às nervuras coletoras.

Oblonga: diz-se da forma da folha simétrica regular, em que o eixo longitudinal é maior do que o transversal e este é quase uniforme ao longo daquele, isto é, os bordos são quase paralelos na maior parte da extensão do limbo foliar.

Obtusa (base): diz-se de uma base quando suas margens aproximam-se entre si em um ângulo maior que $90^{\circ}$.

Opostas: filotaxia onde as folhas se dispõem aos pares em cada nó.

Pecíolo: estrutura popularmente denominada de cabinho, que faz a ligação entre a porção laminar da folha e o caule.

Pericarpo: parede do fruto.

Periderme: tecido de proteção que reveste externamente a raiz e o caule em substituição à epiderme quando esta é eliminada durante o crescimento secundário, incluí súber, felogênio e feloderme.

Pétala: parte da flor, geralmente com colorido conspícuo; uma das unidades da corola.

Piloso (a): superfície que possui pelos (tricomas).

Seco (fruto): frutos que possuem pericarpo seco quando maduros.

Secundárias (nervuras): denominação dada às nervuras que partem da nervura central da folha.

Semente: estrutura formada pelo óvulo desenvolvido após a fertilização.

Serícea: coberto de pelos finos, geralmente curtos e aplicados sobre a superfície do órgão que tem brilho de seda.

Simples (folhas): lâmina inteira, não dividida em folíolos.

Sinonímia: conjunto de nomes aplicados a um determinado táxon, mas que não representam nomes aceitos.

Súber: denominação do tecido morto que reveste o tronco de um vegetal em crescimento secundário.

Sub-cordada: quase cordada.

Sub-coriácea: quase coriácea.

Tanino: grupo de compostos fenólicos que tem como principal característica a afinidade em se ligar a cadeias de proteínas e precipitá-las.

Tronco: porção caulinar lenhosa não ramificada na base das árvores.

Truncado: que termina por uma linha ou plano perpendicular ao comprimento ou à altura.

Valva: Cada uma das peças em que se abrem longitudinalmente as cápsulas, vagens e outros frutos secos e deiscentes.

Verticilada: filotaxia na qual mais de duas folhas se dispõem em um mesmo nó.

Vináceas: com coloração vinho.

Xilema: Tecido vascular, através do qual a maior parte da água e sais minerais é conduzida na planta.

\section{Catálogo das espécies de Vochysiaceae existentes na trilha da Reserva Legal do Campus de Bauru da UNESP}

\section{Qualea cordata Spreng. (Prancha 1, figura 2)}

Nomes populares: carvãozinho, dedaleira-preta.

Ocorrência: cerrado típico e cerradão.
Características morfológicas: HÁBITO: Árvore até 5m. CAULE: tronco, fendilhado, ramos não descamantes. FOLHAS: simples, opostas, cartáceas a coriáceas, glabras ou glabrescentes na face abaxial da folha, com até $8 \mathrm{~cm}$ de comprimento e $3 \mathrm{~cm}$ de largura, com glândulas (nectários extra-florais) na base do pecíolo, nervuras secundárias paralelas e visíveis na face abaxial da folha; nervura evidente ao longo da margem (nervuras coletoras), margem inteira, levemente ondulada, ápice agudo a acuminado e base cordada. FLORES: pétala serícea na face adaxial. Brancas com manchas 


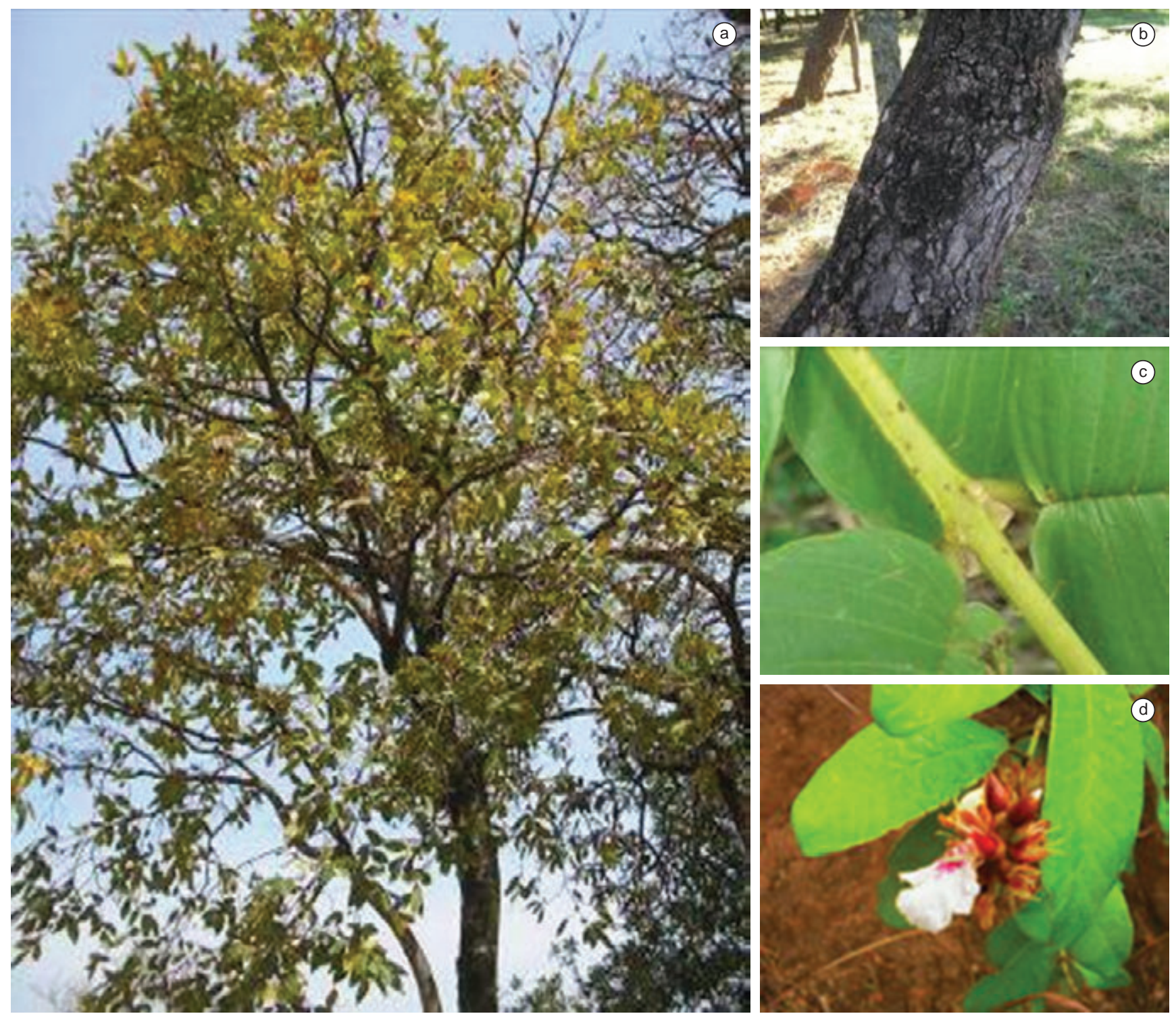

Figura 2. Prancha 1. Qualea cordata Spreng. (Figura 2a hábito, Figura 2b caule, Figura 2c folha, Figura 2d flor).

Figure 2. Plate 1. Qualea cordata Spreng. (Figure 2a habit, Figure 2b stem, Figure 2c leaf, Figure 2d flower).

vináceas, tornando-se amarela após a fase fértil. FRUTOS: cápsula loculicida, 3-valvar cerca de $2 \mathrm{~cm}$ de comprimento. SEMENTES: oblongas com ala lateral. POLINIZAÇÃO: entomófila, tendo como polinizador principal abelhas grandes. DISPERSÃO: anemocórica. ETNOBOTÂNICA: não foram encontrados registros na literatura que descrevessem o perfil fitoquímico desta espécie vegetal, bem como nenhuma evidência de atividade biológica de interesse médico ou comercial a ela creditada.

\section{Qualea grandiflora Mart. (Prancha 2, figura 3)}

Nomes populares: pau-terra, pau-terra-do-campo, pau-terra-defolha-grande.

Ocorrência: cerrado típico e cerradão.

Características morfológicas: HÁBITO: Árvore até $12 \mathrm{~m}$. CAULE: tronco, descamante em pequenas placas, ramos também com essas características. FOLHAS: simples, opostas, coriáceas, pilosas, cerca de $15 \mathrm{~cm}$ de comprimento e $4 \mathrm{~cm}$ de largura, com glândulas (nectários extra-florais) na base do pecíolo, nervuras secundárias paralelas e bastante proeminentes na face abaxial da folha, nervura evidente ao longo da margem (nervuras coletoras), margem inteira, ondulada, ápice agudo ou obtuso acuminado e base arredondada a subcordada. FLORES: amarelo-ouro, pétala glabra. FRUTOS: cápsula loculicida, 3-valvar, cerca de $8 \mathrm{~cm}$ de comprimento. SEMENTES: oblongas com ala lateral. POLINIZAÇÃO: esfingófila. DISPERSÃO: anemocórica. ETNOBOTÂNICA: É empregada na indústria madeireira, e no paisagismo. É utilizada como lenha, além de possuir propriedades medicinais. CURIOSIDADES: esta planta apresenta os frutos ao longo de todo o ano. Possui folha, flores e frutos de dimensões maiores que as outras espécies do gênero Qualea.

\section{Qualea multiflora Mart. (Prancha 3, figura 4)}

Nomes populares: cinzeiro, pau-terra-do-campo, pau-terra-decasca-lisa.

Ocorrência: cerrado típico e cerradão.

Características morfológicas: HÁBITO: árvore até $6 \mathrm{~m}$. CAULE: tronco, com sulcos finos horizontais e aspecto liso. FOLHAS: simples, opostas ou verticiladas, cartáceas a subcoriáceas, glabras, cerca de $8 \mathrm{~cm}$ de comprimento e $3 \mathrm{~cm}$ de largura, com glândulas 
Uma proposta de material didático para o ensino de botânica e ecologia
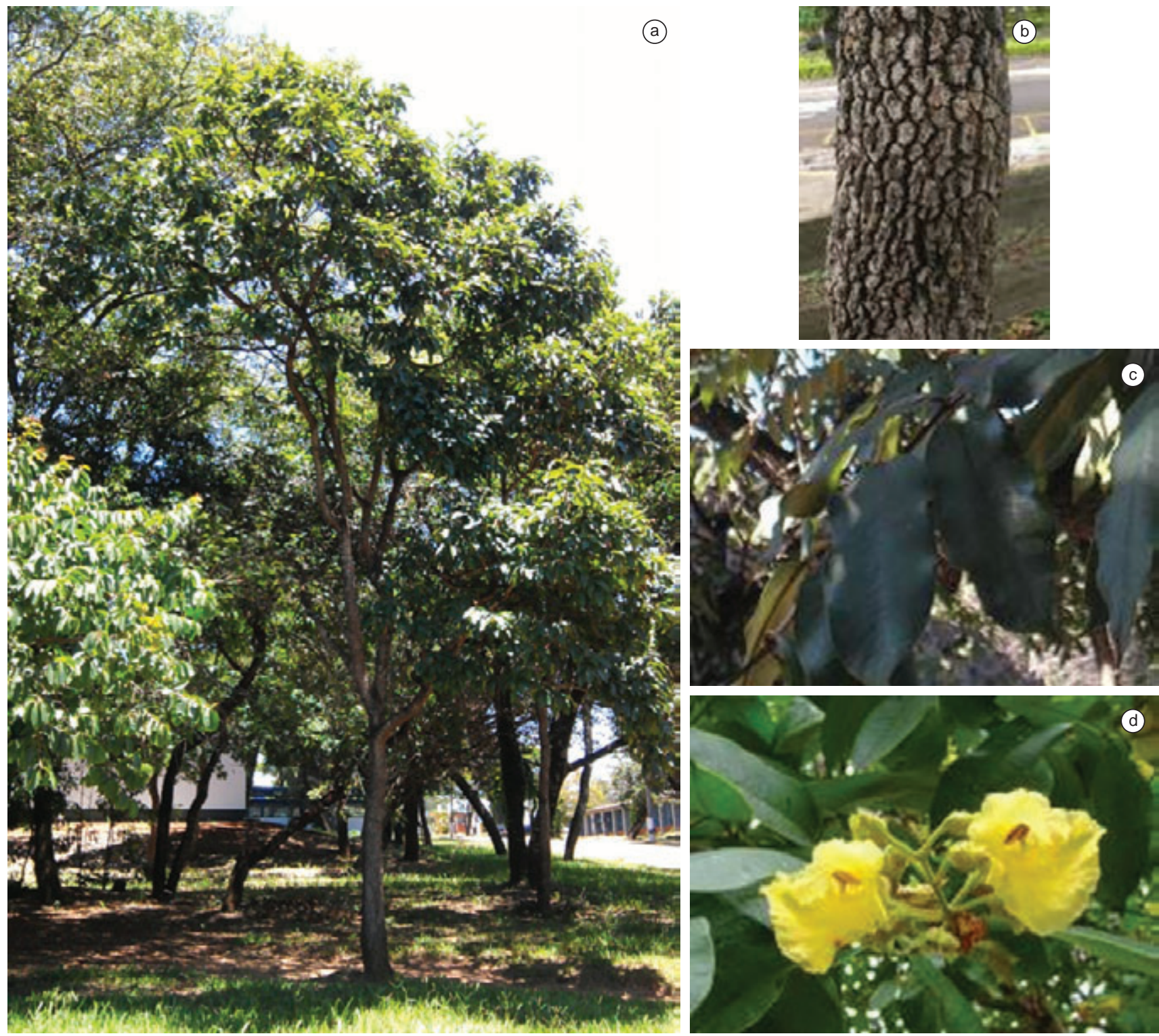

Figura 3. Prancha 2. Qualea grandiflora Mart. (Figura 3a hábito, Figura 3b caule, Figura 3c folha, Figura 3d flor).

Figure 3. Plate 2. Qualea grandiflora Mart. (Figure 3a habit, Figure 3b stem, Figure 3c leaf, Figure 3d flower).

(nectários extra-florais) na base do pecíolo, nervuras secundárias paralelas e visíveis na face abaxial da folha, nervura visível ao longo da margem (nervuras coletoras), margem inteira, plana, ápice acuminado, base arredondada, indumento pode estar presente. FLORES: brancas com linhas amarelas e manchas róseas na região central da face adaxial, tornando-se amarelo claras ou cremes, com linhas amarelas e manchas arroxeadas na região central da face adaxial após a polinização. FRUTOS: cápsula loculicida 3-valvar, superfície lisa, cerca de $4 \mathrm{~cm}$ de comprimento. SEMENTES: oblongas com ala lateral. POLINIZAÇÃO: entomófila, tendo como polinizador principal abelhas grandes. DISPERSÃO: anemocórica. ETNOBOTÂNICA: possui emprego no paisagismo, é utilizada como lenha e em artesanatos. CURIOSIDADES: esta planta apresenta frutos ao longo de todo o ano.

\section{Qualea parviflora Mart. (Prancha 4, figura 5)}

Nome popular: pau-terrra-de-folha-miúda.

Ocorrência: cerrado típico e cerradão.
Características morfológicas: HÁBITO: Árvore até $10 \mathrm{~m}$ de altura. CAULE: tronco fendilhado. FOLHAS: simples, opostas ou verticiladas, curto-pecioladas, cartáceas a subcoriáceas, glabras na face abaxial da folha, face adaxial cano-pubescente, cerca de $6 \mathrm{~cm}$ de comprimento e 2,5 cm de largura, com glândulas (nectários extraflorais) na base do pecíolo, nervura secundárias paralelas e visíveis na face abaxial da folha, nervura ao longo da margem evidente (nervuras coletoras), margem inteira, plana, ápice agudo, obtuso ou truncado e base obtusa, arredondada ou truncada. FLORES: violáceas com manchas arroxeadas e linha branca central na face adaxial. FRUTOS: cápsula loculicida 3-valvar, com superfície descamante, cerca de 3,5 cm de comprimento. SEMENTES: oblongas com ala lateral. POLINIZAÇÃO: entomófila, tendo como polinizador principal abelhas grandes. DISPERSÃO: anemocórica. ETNOBOTÂNICA: possui emprego na indústria madeireira, é utilizada no paisagismo, possui propriedades medicinais. Sua casca é rica em tanino.

CURIOSIDADES: esta planta apresenta frutos ao longo de todo o ano. 

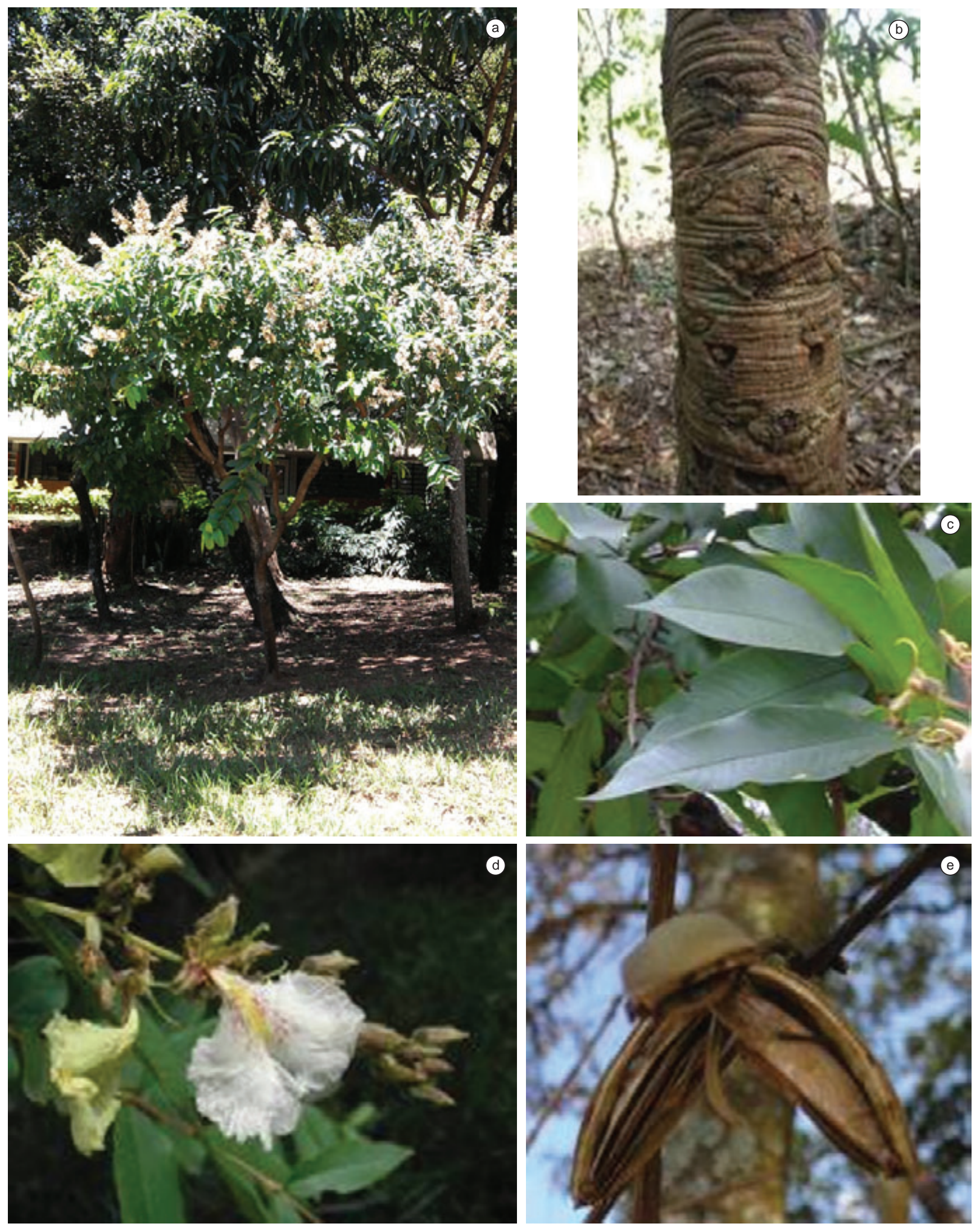

Figura 4. Prancha 3. Qualea multiflora Mart. (Figura 4a hábito, Figura 4b caule, Figura 4c folha, Figura 4d flor, Figura 4e fruto).

Figure 4. Plate 3. Qualea grandiflora Mart. (Figure 4a habit, Figure 4b stem, Figure 4c leaf, Figure 4d flower, Figure 4e fruit). 

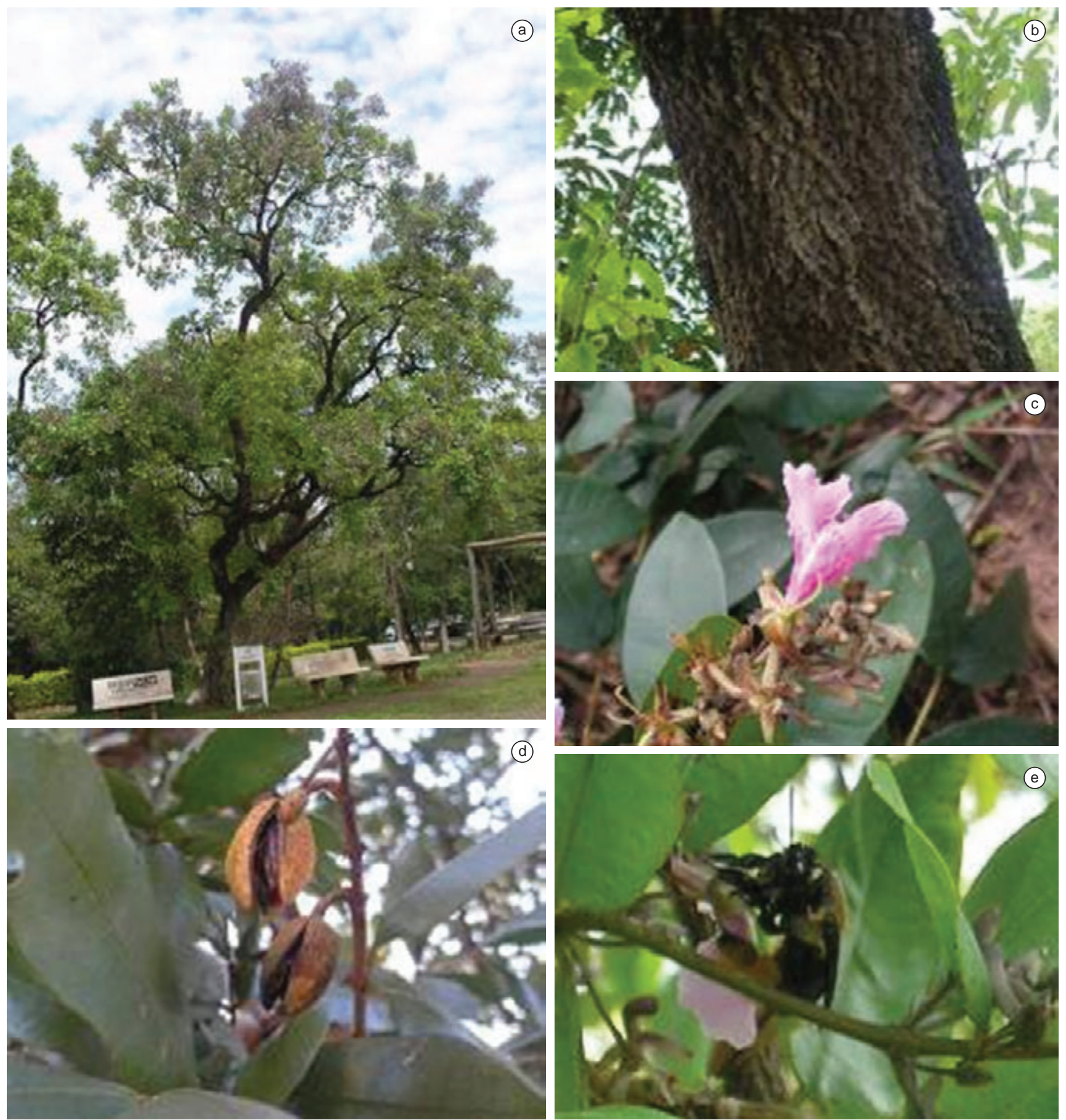

Figura 5. Prancha 4. Qualea parviflora Mart. (Figura 5a hábito, Figura 5b caule, Figura 5c flor, Figura 5d fruto, Figura 5e interação ecológica).

Figure 5. Plate 4. Qualea parviflora Mart. (Figure 5a habit, Figure 5b stem, Figure 5c flower, Figure 3d fruit, 5e ecological interaction).

\section{Vochysia cinnamomea Pohl (Prancha 5, figura 6)}

Nomes populares: pau-doce, casca-doce, quina-doce.

Ocorrência: cerrado típico e cerradão.

Características morfológicas: HÁBITO: árvore até 10 m de altura. CAULE: tronco suberoso sem cristas irregulares. FOLHAS: simples, verticiladas, coriáceas, pilosas, discolores, coloração ferrugínea na face abaxial da folha e face adaxial verde, cerca de $15 \mathrm{~cm}$ de comprimento e $4 \mathrm{~cm}$ de largura, margem inteira, ápice arredondado e base aguda a cuneada. INFLORESCÊNCIA: amarela. FRUTOS: cápsula loculicida 3-valvar, cerca de $3 \mathrm{~cm}$ de comprimento. SEMENTES: oblongas com alas unilaterais. POLINIZAÇÃO: entomófila, tendo como polinizador principal abelhas grandes. DISPERSÃO: anemocórica. ETNOBOTÂNICA: possui emprego na indústria madeireira, é utilizada no paisagismo. Os frutos secos são utilizados para a confecção de artesanato. CURIOSIDADES: esta planta apresenta frutos ao longo de todo o ano. Durante o estudo da fenologia, os indivíduos que se localizavam em um ambiente totalmente sombreado, não floresceram. 

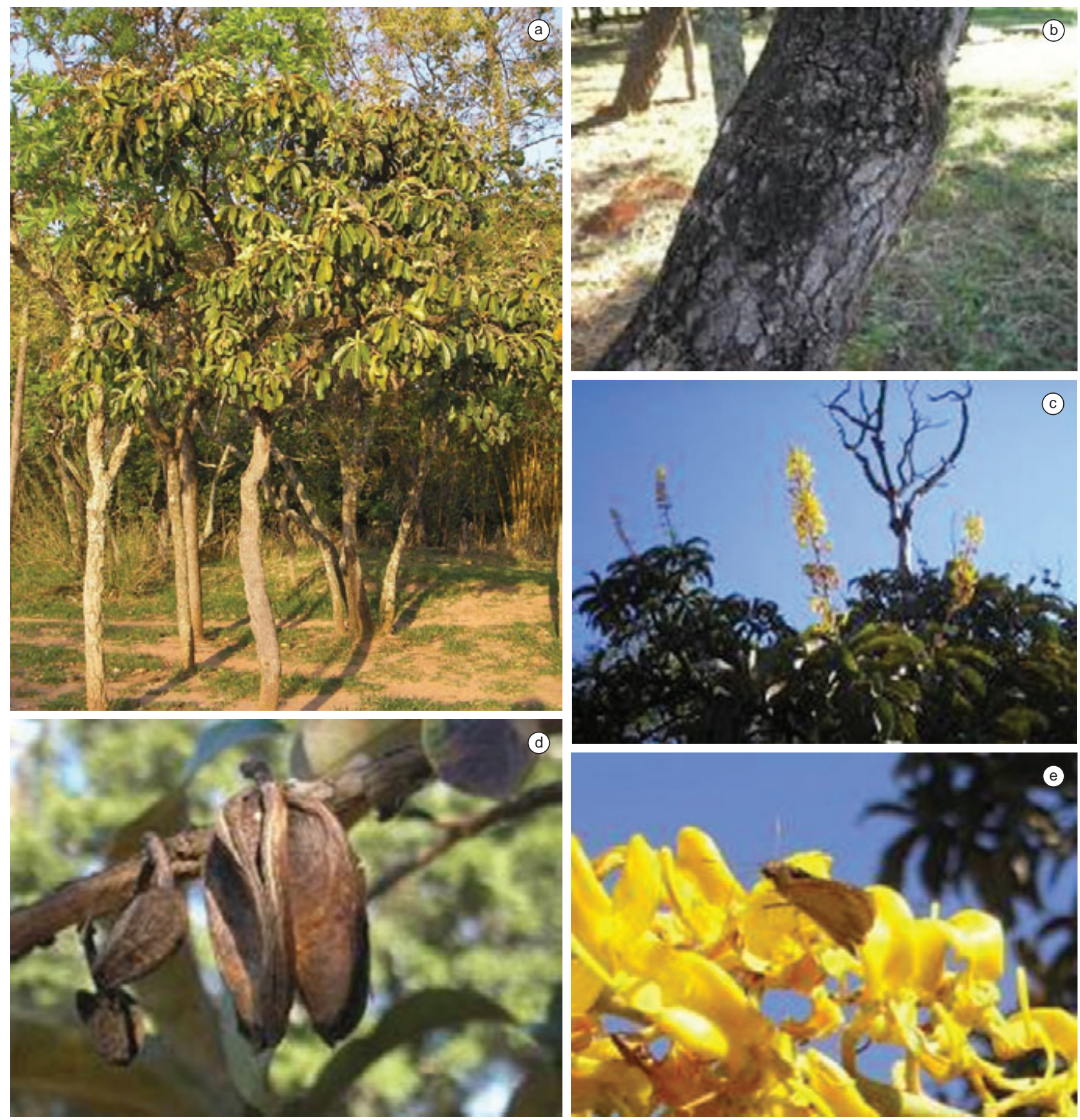

Figura 6. Prancha 5. Vochysia cinnamomea Pohl (Figura 6a hábito, Figura 6b caule, Figura 6c inflorescência, Figura 6d fruto, Figura 6e interação ecológica).

Figure 6. Plate 5. Vochysia cinnamomea Pohl (Figure $6 \mathrm{a}$ habit, Figure $6 \mathrm{~b}$ stem, Figure $6 \mathrm{c}$ infllorescence, Figure 6d fruit, Figure $6 \mathrm{e}$ ecological interaction).

\section{Vochysia tucanorum Mart. (Prancha 6, figura 7)}

Nomes populares: cinzeiro, pau-de-tucano, pau-doce.

Ocorrência: cerrado típico e cerradão.

Características morfológicas: HÁBITO: árvore de até $12 \mathrm{~m}$ de altura. CAULE: tronco, súber espesso com cristas irregulares. FOLHAS: simples, verticiladas, coriáceas, glabras, lustrosas, concolores, cerca de $15 \mathrm{~cm}$ de comprimento e $4 \mathrm{~cm}$ de largura, margem inteira, ápice arredondado, base aguda. INFLORESCÊNCIA: amarela. FRUTOS: cápsula loculicida 3-valvar, cerca de $2 \mathrm{~cm}$ de comprimento. SEMENTES: oblongas com alas unilaterais. POLINIZAÇÃO: entomófila, tendo como polinizador principal abelhas grandes. DISPERSÃO: anemocórica. ETNOBOTÂNICA: possui emprego na indústria madeireira, no paisagismo, além de possuir propriedades medicinais. CURIOSIDADES: O nome popular pau-de-tucano advém da impressão que se tem, quando observada ao longe e na época da floração, de que a árvore esteja recoberta por tucanos, uma vez que a inflorescência lembra o bico de um tucano. É comum a presença de resina em seu tronco, isso se deve à raspagem feita por saguis para se alimentarem. 

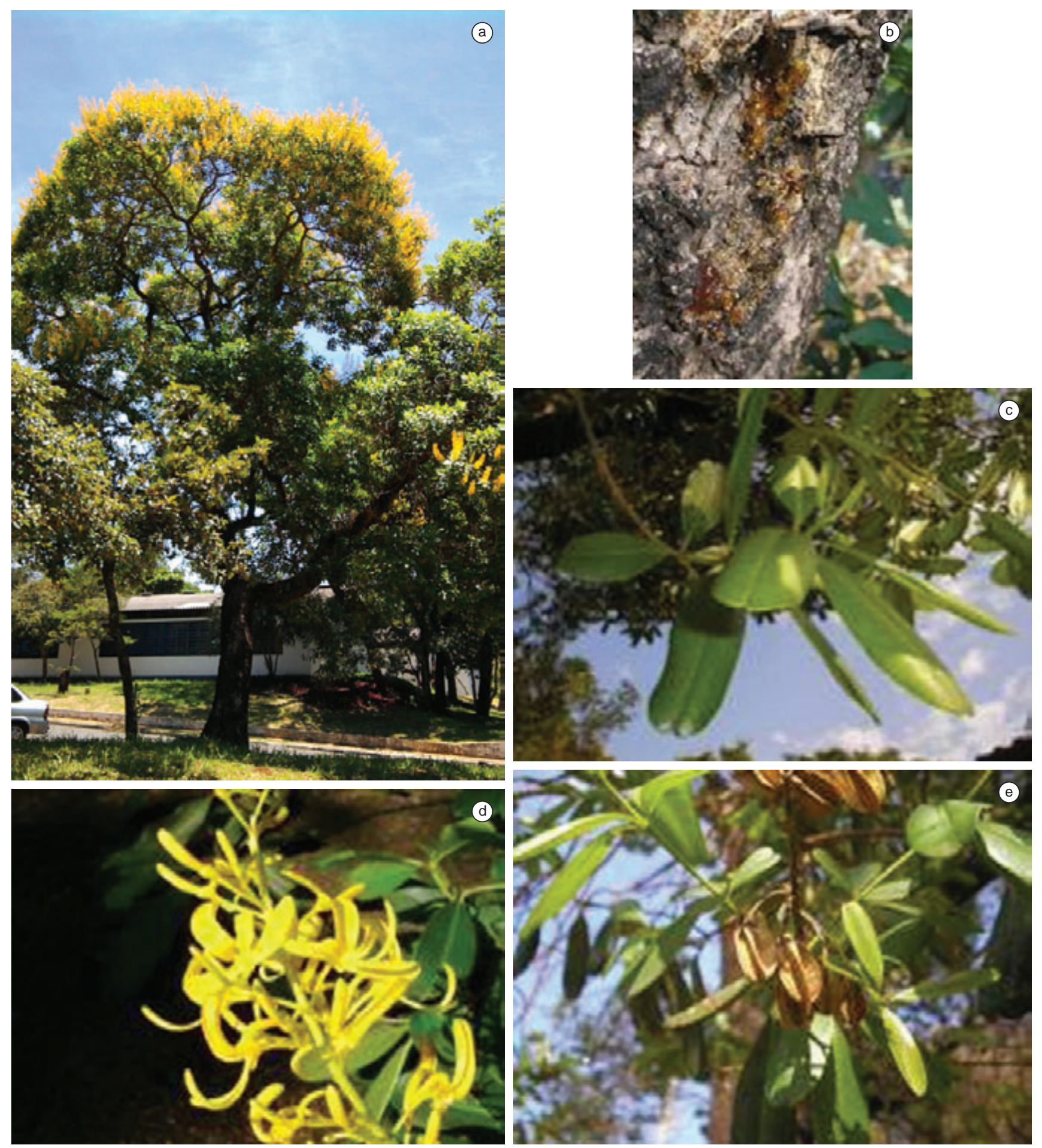

Figura 7. Prancha 6. Vochysia tucanorum Mart. (Figura 7a hábito, Figura 7b caule, Figura 7c folha, Figura 7d inflorescência, Figura 7e fruto).

Figure 7. Plate 6. Vochysia tucanorum Mart. (Figure 7a habit, Figure 7b stem, Figure 7c leaf, Figure 7d inflorescence, Figure 7e fruit). 